This PDF is a selection from an out-of-print volume from the National Bureau of Economic Research

Volume Title: International Volatility and Economic Growth: The First Ten Years of The International Seminar on Macroeconomics

Volume Author/Editor: Georges de MÃ@nil and Robert J. Gordon, editors

Volume Publisher: Elsevier Science Publishers B.V., 1991

Volume ISBN: 0-444-89284-2

Volume URL: http://www.nber.org/books/de_m91-2

Conference Date: various

Publication Date: January 1991

Chapter Title: Current and Anticipated Deficits, Interest Rates and Economic Activity

Chapter Author: Olivier J. Blanchard

Chapter URL: http://www.nber.org/chapters/c11687

Chapter pages in book: (p. 361 - 390) 


\title{
CURRENT AND ANTICIPATED DEFICITS, INTEREST RATES AND ECONOMIC ACTIVITY
}

\author{
Olivier J. BLANCHARD* \\ Massachusetts Institute of Technology, Cambridge, MA 02139, USA
}

There is a widespread feeling that current deficits, in Europe and the U.S., may hurt rather than help the recovery. This paper examines some of the issues involved, through a sequence of three models. The first model focuses on sustainability and characterizes its determinants. It suggests that the issue of sustainability may indeed be relevant in some countries. The second model focuses on the effects of fiscal policy on real interest rates, and in particular on the relative importance of the level of deficits and the level of debt in determining interest rates. The third model focuses on the effects of fiscal policy on the speed of the recovery. It shows how a sharply increasing fiscal expansion might be initially contractionary rather than expansionary.

\section{Introduction}

The size of fiscal deficits is becoming a major source of concern. In Europe and Japan, the large current deficits are inhibiting the use of further, even temporary, fiscal expansion; indeed at the bottom of a recession, most governments are attempting to reduce spending and increase tax revenues. In the United States on the other hand, where current deficits are large and anticipated deficits much larger, there is widespread concern that they may slow or even prevent a complete recovery.

The perception that deficits may hurt rather than help the recovery is clearly at odds with the traditional view that deficits, although they will in general increase interest rates, will nevertheless increase demand and economic activity. Although no unified or well articulated 'new view' has emerged, challengers of the traditional view insist on the abnormally large size of current deficits. Such deficits, they argue, may be simply unsustainable, a possibility never considered by the traditional view. They may be so large and so prolonged that the increase in real interest rates may more than offset their direct expansionary effect. The purpose of this paper is to see whether this new view has some validity, and more generally to reexamine the relation between debt, deficits, interest rates, and economic activity.

The first issue taken up in the paper is that of sustainability. Is it the case that some countries are running unsustainable deficits and may be forced, at

*I thank Eliana Cardoso, Rudiger Dornbusch, Benjamin Friedman, and my discussants, Edmond Malinvaud and Stephen Marris, for useful suggestions and discussions. I also thank the Sloan Foundation for financial support. 
some time in the future, to repudiate the debt either explicitly or through inflation depreciation? If this was the case, the increased uncertainty generated by deficits might well offset their expansionary effect. The purpose of the first model is thus to clarify the notion of sustainability and to think about its determinants. A casual examination of the evidence suggests that sustainability may indeed have become a relevant issue in some European countries.

The second issue taken up is that of the relation between real rates, debt, and deficits. Even if deficits are sustainable, they will affect interest rates. Do interest rates, however, depend on the level of debt, or on the level of deficits, or on both? These are the questions addressed in the second model of the paper. Central to this set of issues is the question of the horizon of agents, as we know that if agents have infinite horizons, interest rates may depend neither on debt nor on deficits. The main element of the model is thus the derivation of an aggregate consumption function which does not satisfy Ricardo-Barro equivalence. The model shows that long real rates depend on the anticipated sequence of debt, or equivalently on the current level of debt and the anticipated sequence of deficits.

The third and last issue is that of potentially perverse effects of deficits on output. Can deficits increase real rates by so much as to decrease aggregate demand and output? The third model builds on the previous one but allows for an effect of aggregate demand on output. Its main conclusion is that, although current deficits are expansionary, the anticipation of growing deficits may well reduce economic activity. This suggests that the fiscal program of the current U.S. administration could be currently contractionary rather than expansionary.

The paper has four sections. Section 2 presents briefly the basic facts about debt, current and anticipated deficits, and spending levels. Section 3 focuses on sustainability. Section 4 and 5 characterize the relation between debt, deficits, interest rates, and output.

\section{Basic statistics}

The relevant basic statistics are presented for the U.S. and eight EEC countries in table 1 .

Focusing first on debt, we find that the average ratio of debt to GDP is relatively low by historical standards. There are, however, wide variations of this ratio across countries, from $16 \%$ in Denmark to $98 \%$ in Ireland. (These inter-country variations are no wider than intra-country variations over time: the ratio fell in the U.S. from $100 \%$ in 1947 to $25 \%$ in the mid 70 's.)

Turning to deficits, we see that they are large by historical standards; this is true for both 1982 and projected 1983 deficits and still holds after inflation correction of nominal interest payments on government debt, as shown in 


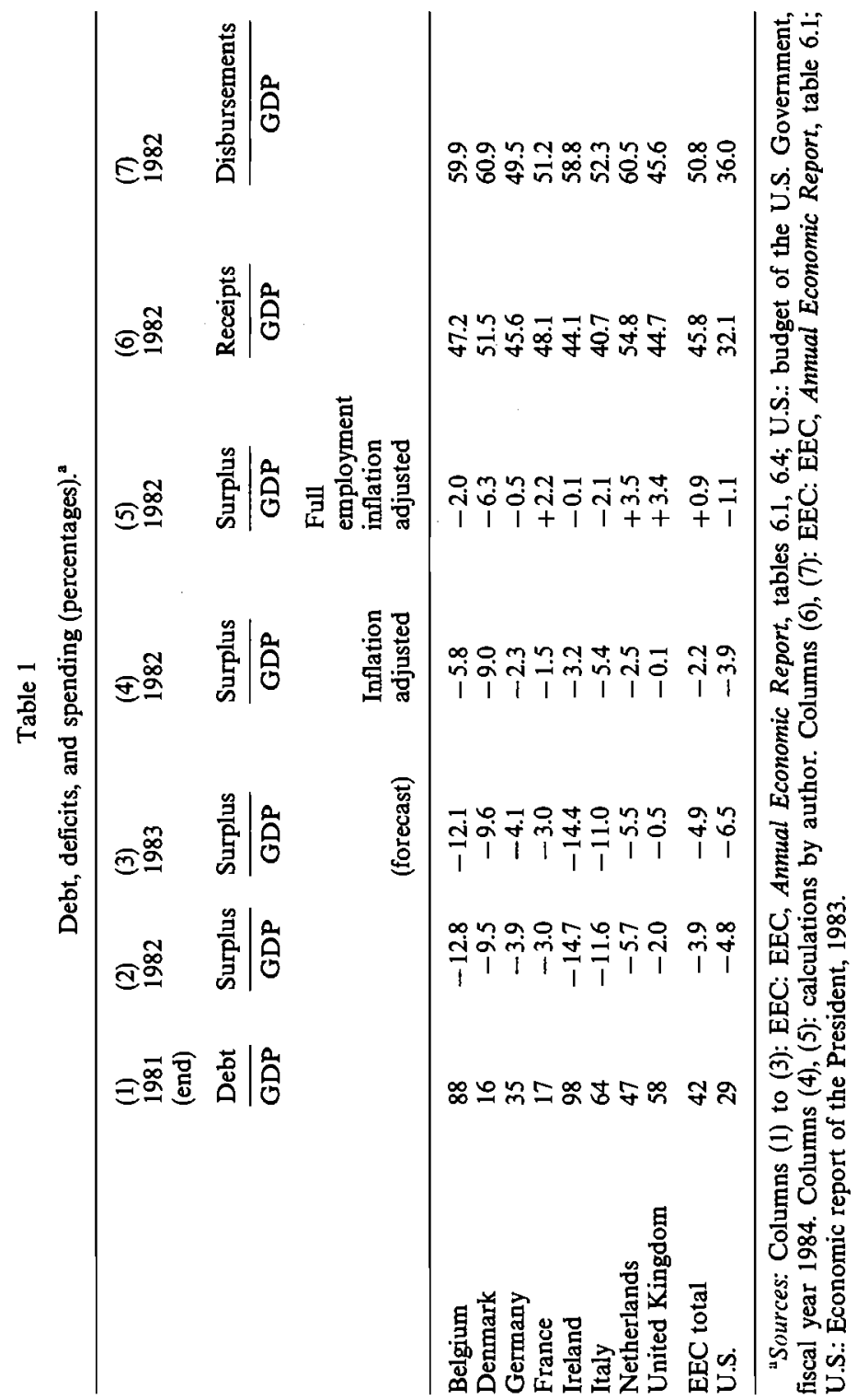


column (4). Column (5) shows, however, that with some exceptions, the current deficits are largely cyclical: if there was no change in fiscal policy, they would disappear as the world economy returned to full employment. As return to full employment is still far in the future, these full employment surpluses would still correspond to actual deficits until at least the mid 80's.

Most countries, therefore, do not currently have structural deficits. There is, however, evidence in the U.S. of looming structural deficits starting in 1983 and, in the absence of further changes in fiscal policy, averaging $6 \%$ of GNP for the rest of the decade. ${ }^{1}$ Two of the proximate causes, the income tax cuts voted in 1981 and the increase in defense spending, are clearly specific to the U.S. The third, the increase in real interest rates, is common to all countries, affecting them in proportion to their debt to GDP ratios. The stance of discretionary fiscal policy is quite different outside of the U.S.: cyclically adjusted budget deficits have been and are expected to be reduced by $0.5 \%$ in $1981,0.8 \%$ in 1982 , and $1.2 \%$ in 1983 in Japan, and $0.9 \%$ in 1981 , $1.4 \%$ in 1982 , and $1.2 \%$ in 1983 for the EEC as a whole. ${ }^{2}$

Finally, although the focus of the paper is on deficits, that is, on decreases in taxes given spending, it is important to remember what has happened to government spending. Except in the U.S., the level of spending has steadily gone up over time. The ratio of government outlays to GDP for the EEC as a whole has increased by $10 \%$ since 1970 , by $15 \%$ since 1960 . Columns (6) and (7) show how high the levels are. It is not unlikely that some of the problems attributed to deficits come in fact from the levels of government spending and that some arguments against deficits are really arguments against the level of spending.

\section{Sustainability of deficits}

What does it mean to say that a given combination of debt and deficits is unsustainable? To answer that, we can start with the government budget constraint

$$
\dot{D}=r D+G-T
$$

$D$ is government debt and the deficit is assumed to be entirely debt financed. $r$ is the real interest rate, $G$ and $T$ spending and taxes, respectively. Let's further define $\bar{T}$ as the maximum amount of taxes which can be collected by the government and $\underline{G}$ as the minimum socially acceptable amount of government outlays. Both, and especially the second one, are admittedly fuzzy and would be difficult to determine empirically. Consider the level of debt $\bar{D}=r^{-1}(\bar{T}-\underline{G})$ : if debt ever exceeds $\bar{D}$, the level of debt will

\footnotetext{
'Budget of the U.S. Government, fiscal year 1984, section 3-31.

'Sources: OECD Economic Outlook, December 1982, table 9, and Annual Economic Report, EEC, November 1982.
} 
be forever increasing. The government will be in effect running a Ponzi scheme and will ultimately have to repudiate its debt. The implication is that the government cannot sell debt beyond $\bar{D}$, which is therefore the maximum sustainable level of debt. ${ }^{3}$ If, for example, $\bar{T}-\underline{G}$ is equal to $10 \%$ of the GNP and $r$ to $5 \%, \bar{D}$ is 2 times GNP. This shows why the issue of sustainability has arisen in parallel with increases in real interest rates. Sustainable levels of debt are very large at the historical level of real rates of $1-2 \%$, much smaller at the current $3-6 \%$.

This computation is too simple for many reasons. It is too pessimistic in that it does not take into account GNP growth which increases the sustainable ratio of debt to GNP, and does not allow for possible monetization and the use of the inflation tax. ${ }^{4}$ It is also too optimistic for at least two reasons: The first is that, unless Ricardo-Barro equivalence holds, $r$ itself is likely to be an increasing function of the level of debt. The second is that increases in the tax burden or decreases in spending can only happen gradually. It is this element which is currently used to argue against a temporary fiscal expansion; many doubt that the new spending programs can indeed be only temporary. It is this last argument that we now formalize. Let

$$
\begin{array}{ll}
\dot{D}=r D-X, & X \equiv T-G, \\
\dot{X} \leq \alpha(\bar{X}-X), & \bar{X} \equiv \bar{T}-G>0 .
\end{array}
$$

$X$ is the budget surplus (deficit if negative) before interest payments. Eq. (2) says that the gap between $\bar{X}$, the maximum surplus, and $X$ can only be reduced at rate $\alpha .{ }^{5}$ We now want to know whether a given pair $\left(X_{0}, D_{0}\right)$ [or equivalently $\left.\left(\dot{D}_{0}, D_{0}\right)\right]$ is sustainable or not. We can draw the phase diagram of the system, with the inequality in (2) replaced by an equality. This is done in fig. 1. The equilibrium is a saddle point, with stable arm $A A^{\prime}$. Consider point $C$. Point $C$ is not sustainable as, even if the deficit is reduced as fast as feasible, i.e., if (2) holds with equality, the maximum level of debt $\bar{D}$ is reached before deficits are eliminated. Point $B$ on the other hand is sustainable as deficits can be eliminated before $D$ reaches $\bar{D} . B F$ represents the fastest feasible path of reduction of deficits. When $F$ is reached, $X$ need not be increased further and (2) holds as an inequality.

The critical locus is therefore the locus $A E$. Pairs $(X, D)$ below it are not

\footnotetext{
${ }^{3}$ For the argument to be complete, it should show why the government cannot issue more and more debt forever and therefore has to repudiate the debt. Dealing with these issues would lead us too far astray.

${ }^{4}$ The maximum inflation tax is relatively small. Unanticipated inflation may, however, if debt is in the form of long term bonds with nominal coupons, substantially reduce the real value of the debt.

${ }^{5} \mathrm{An}$ interesting attempt to estimate OECD fiscal reaction functions in this light and to study implications for structural deficits is described in Hubbard (1983).
} 


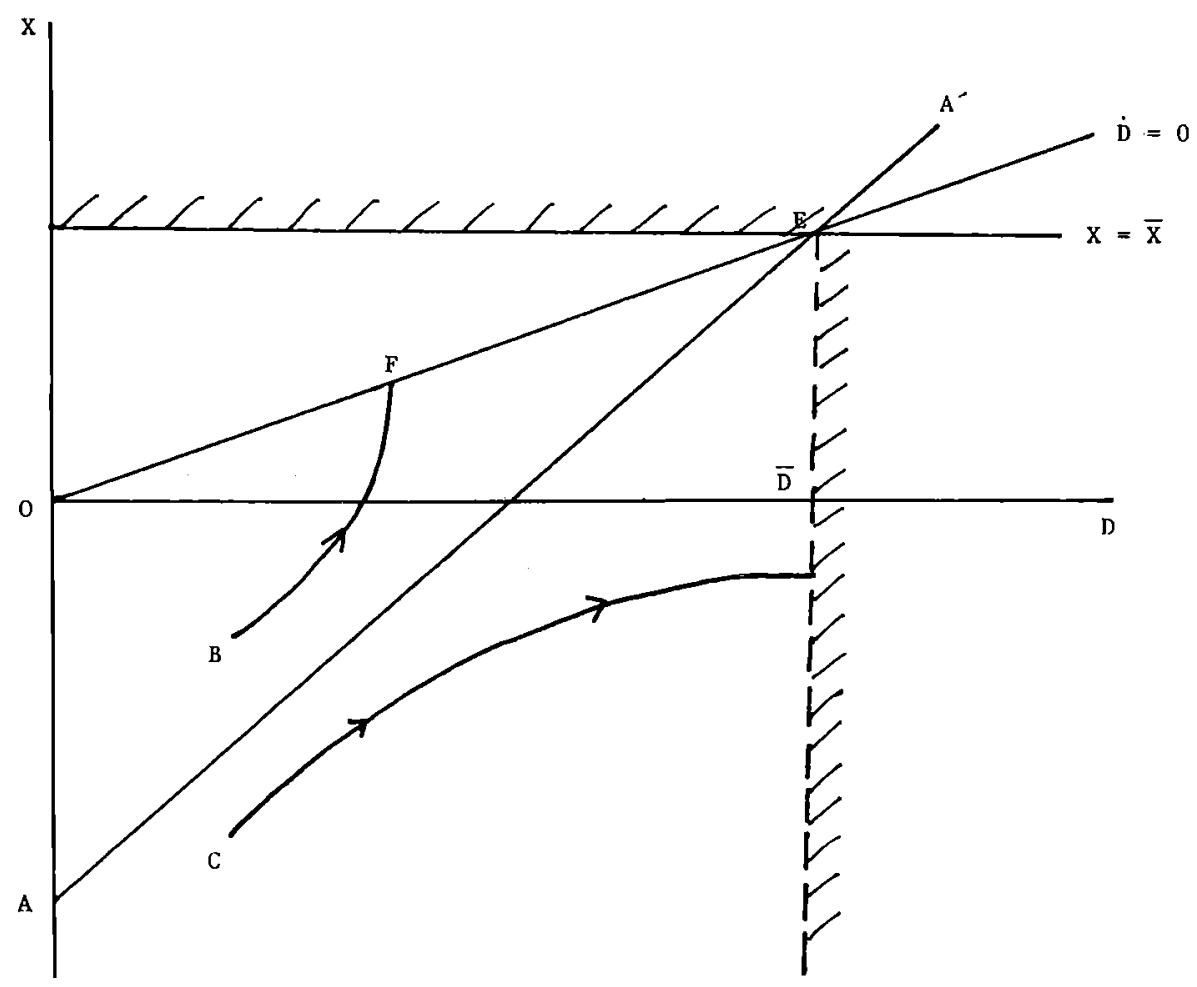

Fig. 1. Sustainable deficit debt pairs.

sustainable and pairs above it are. It is given by ${ }^{6}$

$$
(r+\alpha)(D-\bar{D})-(X-\bar{X})=0, \quad \bar{D}=r^{-1} \bar{X} .
$$

The sustainability condition for a given $\left(X_{0}, D_{0}\right)$ is therefore

$$
(r+\alpha)\left(D_{0}-\bar{D}\right)-\left(X_{0}-\bar{X}\right) \leq 0
$$

If $\alpha=\infty$, so that there are no restrictions on changes in $X$, the condition is again that $D_{0}$ be less than $\bar{D}$. If $\alpha=0$, the condition reduces to $\dot{D} \leq 0$ : there cannot be a positive deficit.

Eq. (3) shows the role of the speed of adjustment $\alpha$, the interest rate, the level of debt, the actual deficit, and the maximum potential surplus. Returning to table 1, Ireland and Belgium with their large debt, deficits, and

${ }^{6}$ The roots of the system (1), (2) (with equality) are $r$ and $-\alpha$. The characteristic vector associated with $\alpha,\left(x_{1}, x_{2}\right)$, is such that $x_{1} / x_{2}=(r+\alpha)^{-1}$. Thus $D-\bar{D}=c_{1}(r+\alpha)^{-1} \mathrm{e}^{-a 1}$ and $X-\bar{X}=c_{1} \mathrm{e}^{-a t}$. Taking the ratio gives the equation in the text. 
level of spending seem to be the countries most likely to violate (3). We can attempt some crude computations for Belgium, for example. Using the implied values from table 1 for $D, X^{7}$ together with $r=5 \%$ and $\alpha=20 \%$ implies that $\bar{X}$ be at least equal to $7.5 \%$ for the inequality (3) to be satisfied. At the current level of 'spending, this would imply a ratio of receipts to GDP of close to $60 \%$, which appears very high. ${ }^{8}$ Thus sustainability might indeed be an issue; it appears to be less so in other countries.

The model does not tell us what happens when a current fiscal program appears unsustainable. It is likely that a program does not suddenly become unsustainable but rather that agents start taking the possibility of repudiation into account. What happens depends on the type of repudiation that agents anticipate. If they anticipate attempts to depreciate the debt through inflation at some point in the future, they will require higher nominal interest rates on new issues of public and private bonds. Only if public debt is of sufficiently long maturity can the government successfully use inflation to repudiate part of the debt. If agents anticipate repudiation of government debt only - a less likely case - they will require a higher real rate on government debt than on private debt so as to be compensated for the risk of repudiation. In both cases, a shift in demand towards short maturity debt is likely.

\section{Interest rates, debt, and deficits at full employment}

This section focuses on the effects of debt and deficits on the equilibrium sequence of interest rates in a full employment economy. This is needed to understand their effects in an economy which may not be at full employment; it is also of more than academic interest as some of the larger anticipated U.S. deficits are expected to take place in an economy which should be by then at full employment.

The first step is to construct a consumption function consistent with nonneutrality of debt; the second is to close the model to derive equilibrium interest rates.

\subsection{Aggregate consumption}

Aggregate consumption functions derived from individual life cycle behavior are usually intractable, for individuals differ in two respects, making

\footnotetext{
${ }^{7}$ Interest payments were equal to $7.8 \%$ of GDP in 1982, and have to be deducted from disbursements to get $G$.

${ }^{8}$ The medium term budgetary objectives, as of fiscal year 1982, for Belgium are of a reduction of the general government deficit from $12.8 \%$ in 1982 to $7 \%$ in 1985 . This is to be achieved partly through a reduction iñ spending. (Source: OECD, Public Sector Deficits: Problems and Policy Implications, Occasional Papers, June 1983). The June 1983 EEC projections of deficits in Belgium are, however, 11.7\% for 1983 and 12.1\% for 1984 (Source: European Economy, Supplement A, no. 6, June 1983, table 9).
} 
exact aggregation difficult: they have different horizons and thus different propensities to consume out of wealth, as well as different levels of wealth. There is, however, one set of assumptions (and I believe only one) which preserves the assumption of finite horizons, essential to the analysis of debt and deficits but leads to a tractable aggregate consumption function; we now explore it.

Time is continuous. At any instant, a new cohort, composed of many agents, is born, its size normalized to be unity. Agents face, during their lifetime, a constant instantaneous probability of death $p$, so that their expected life is $p^{-1}$. Because of the large number of agents in each cohort, the probability $p$ is also the percentage of agents in each cohort which die at any instant. The size of a cohort born at time zero as of time $t$ is therefore $\mathrm{e}^{-p t}$ and the size of the population at any time $t$ is $\int_{-\infty}^{t} \mathrm{e}^{-p(t-s)} \mathrm{d} s=p^{-1}$. The main implication of this set of assumptions is that, although agents are of different ages, they all have at any time the same expected remaining life, $p^{-1}$, and thus the same marginal propensity to consume out of wealth.

Two additional assumptions, about income distribution and financial markets, considerably simplify the analysis. The first is that all agents alive work and thus share labor income equally. ${ }^{9}$ The second is that agents can save or dissave by buying or selling actuarial bonds rather than regular bonds, i.e., bonds which are cancelled by death. Because of the large number of agents, intermediation between lenders and borrowers can be done risklessly. Lenders lend to intermediaries; these claims are cancelled by death of the lenders. Borrowers borrow from intermediaries; these claims are cancelled by death of the borrower. If the rate of interest on regular bonds is $r$ then arbitrage and the zero profit condition in intermediation imply a rate of interest on actuarial bonds of $(r+p)$. As by assumption agents have no bequest motive, they prefer to borrow and save only through these actuarial bonds. As a result, they leave no bequest [this clever device was introduced by Yaari (1965)]. ${ }^{10}$

The aggregate consumption can now be derived intuitively as follows: (A derivation is given in the appendix.) Assume each agent is an expected utility maximizer, with instantaneous logarithmic utility and subjective discount rate $\theta$. Then, denoting individual variables by lower case letters, his consumption is characterized by

$$
c=(p+\theta)(w+h), \quad h=\int_{i}^{\infty} y_{s} \exp \left\{\int_{t}^{s}\left(r_{v}+p\right) \mathrm{d} v\right\} \mathrm{d} s,
$$

\footnotetext{
${ }^{9}$ Although the model captures the idea that agents do not have infinite horizons, agents in the model do not go through a life cycle. Thus the model cannot be used to examine issues for which the life cycle is essential, such as, for example, saving for retirement or social security.

${ }^{10}$ In the absence of actuarial bonds, agents would not only leave unanticipated bequests but might also go bankrupt. Actuarial bonds allow agents to insure themselves against such contingencies. Their presence simplifies the analysis considerably but is in no way the source of the non-neutrality of deficits or debt.
} 


$$
\dot{w}=(r+p) w+y-c .
$$

$c$ is consumption, $y$ is non-interest income, $w$ and $h$ are non-human and human wealth respectively. The presence of uncertainty about death modifies the standard formulation in two ways: The relevant interest rate is $(r+p)$ rather than $r$; at the same time the marginal propensity to consume out of wealth is $(p+\theta)$ rather than $\theta$.

Aggregate consumption is obtained by aggregating (4) and (5) over all agents alive at time $t$. Denoting aggregate variables by upper case letters, this gives

$$
\begin{aligned}
& C=(p+\theta)(W+H), \quad H=\int_{t}^{\infty} Y_{s} \exp \left\{\int_{t}^{s}\left(r_{v}+p\right) \mathrm{d} v\right\} \mathrm{d} s \\
& \dot{W}=r W+Y-C .
\end{aligned}
$$

Those two equations are similar to the individual equations with one major - difference. Whereas the rate of interest used to discount noninterest income is $(r+p)$, aggregate non-human wealth accumulates at rate $r$, not $(r+p)$. This is because, although the interest on actuarial bonds is $(r+p) W$, a portion, $p W$, is extinguished with the death of wealth holders. Thus, the discount rate for aggregate human wealth $(r+p)$ is higher than the discount rate for aggregate non-human wealth $(r)$. The simple form of the result is due to the existence of actuarial bonds. The qualitative nature of the result, namely the use of a higher discount rate for human than for nonhuman wealth does not depend on the existence of actuarial bonds but on the positive probability of death faced by agents. It is this difference in discount rates which implies non-neutrality of debt and deficits.

\subsection{Debt and interest rates in steady state}

Let us introduce now a government which collects lump sum taxes $T$ on non-interest income, spends $G$ on goods, and has debt oustanding in amount $D$. Debt is in the form of actuarial bonds, so that the budget constraint is

$$
\dot{D}=(r+p) D+G-T-p D=r D+G-T \text {. }
$$

The term $-p D$ again represents the portion of the debt which is extinguished with the death of debt holders. To see why deficits matter, we can integrate eq. (8) forward, subject to the condition that debt reaches some steady state level,

$$
D_{t}+\int_{t}^{\infty} G_{s} \exp \left\{-\int_{t}^{s} r_{v} \mathrm{~d} v\right\} \mathrm{d} s=\int_{t}^{\infty} T_{s} \exp \left\{-\int_{t}^{s} r_{v} \mathrm{~d} v\right\} \mathrm{d} s
$$


From eq. (6), now that non-interest income net of taxes is given by $Y-T$, human wealth is given by

$$
H_{t}=\int_{i}^{\infty} Y_{s} \exp \left\{-\int_{i}^{s}\left(r_{v}+p\right) \mathrm{d} v\right\} \mathrm{d} s-\int_{i}^{\infty} T_{s} \exp \left\{-\int_{i}^{s}\left(r_{v}+p\right) \mathrm{d} v\right\} \mathrm{d} s .
$$

In the absence of changes in government spending, changes in taxes must leave the right-hand side of (9) unchanged. This will, however, change the value of the second term in (10). In effect the government 'discounts' taxes at $r$, agents at $r+p$. Current deficits, that is, lower taxes today and higher taxes later, will, unless $p=0$, increase $H_{t}$ and $C_{t}$ at given interest rates.

To close the model, we simply assume that the economy is an exchange economy, with exogenous output $Y$. Thus in equilibrium, private non-human wealth $W$ is equal to government debt $D$. Equilibrium is, therefore, characterized by

$$
\begin{aligned}
& Y=C+G=(p+\theta)(D+H)+G, \\
& \dot{D}=r D+G-T, \\
& \dot{H}=(r+p) H-Y+T .
\end{aligned}
$$

Eq. (11) is the condition for equilibrium in the goods market. Eqs. (12) and (13) give the dynamic behavior of debt and of human wealth; (13) follows from time differentiation of (10). ${ }^{11}$

In steady state, $\dot{D}=\dot{H}=0$ and this, with some manipulation, implies

$$
\begin{aligned}
& r D=T-G, \\
& r=\theta+(p+\theta) p(D /(Y-G)) .
\end{aligned}
$$

Eq. (14) is the steady state government budget constraint. Eq. (15) characterizes the steady state interest rate (on regular bonds).

If $p=0$, then the interest rate equals the subjective discount rate and is independent of debt and spending. If $p$ is positive, however, the interest rate is an increasing function of both debt and spending; the larger $p-$ the shorter the expected life - the stronger the effect. In order to induce agents to hold the debt, the government must make agents save more; it does so by increasing the interest rate over the subjective discount rate. The formula suggests relatively small effects of debt on interest rates. For example, if we take reasonable upper bounds, say $D / Y=1, G=0.5 Y, \theta=10 \%$, and $p=5 \%$, $r-\theta$ is equal to $1.5 \%$. The strength of this model is, however, not in its quantitative answers and these numbers should be looked at with caution. ${ }^{12}$

\footnotetext{
${ }^{11}$ In this section, no notational distinction is made between actual and expected values. $\dot{H}$, for example, is the expected change in $H$.

${ }^{12}$ Tobin (1967) developed a realistic model of life cycle to look at steady state savings. He did not look, however, at the effects of debt.
} 


\subsection{Dynamic effects of deficits}

Starting from steady state and keeping government spending constant, we now consider changes in the sequence of taxes which satisfy the intertemporal government budget constraint. From goods market equilibrium, given output and government spending, interest rates must be such as to leave consumption and thus the sum of debt and human wealth constant. If $D+H=$ constant, $\dot{D}=-\dot{H}$ and from (12), (13)

$$
r D+(r+p) H=Y-G .
$$

Combining this with (11) gives

$$
r=\theta+p(p+\theta)(D /(Y-G)) .
$$

Thus the relation between interest rates, debt, and government spending holds at any point of time and not only in steady state. The short-term interest rate depends on the current level of debt and does not depend on the current level of deficits: a decrease in taxes, given spending, has no effect on $r$. Deficits will, however, affect anticipated future real rates. To illustrate the effects of deficits on the whole term structure, consider now the sequence of deficits implied by

$$
\dot{D}=r D+G-T(D, x), \quad T_{D}>0, \quad T_{x}>0 .
$$

Taxes are now a function of a shift parameter $x$ and an increasing function of debt. We want to consider only sustainable deficits and thus impose

$$
\mathrm{d} \dot{D} / \mathrm{d} D=D \mathrm{~d} r / \mathrm{d} D+r-T_{D}=2 r-\theta-T_{D}<0 .
$$

This requires that taxes increase sufficiently fast as debt increases thus closing the deficit. Let's further define the long term interest rate' as the yield on consols paying a constant coupon flow of unity. Let $R$ be their yield and thus $1 / R$ be their price. The instantaneous rate of return on consols is

$$
(1+\mathrm{d}(1 / R) / \mathrm{d} t) /(1 / R)=R-\dot{R} / R .
$$

It is the sum of the yield and of the expected capital gain, which is negative if yields increase, or equivalently, if prices decrease. By arbitrage between short and long bonds,

$$
R-\dot{R} / R=r \text {. }
$$

We may now consider the system composed of (16), (17), and (18), which determines the dynamic behavior of debt, short and long rates. ${ }^{13}$ Eliminating

\footnotetext{
${ }^{13}$ The system is in fact recursive. $R$ depends on $D$, but $D$ does not depend on $R$. Consols may actually not be traded at all in the economy. $R$ is introduced to get a convenient characterisation of the term structure, and because it will play an important role in the next section.
} 
$r$ using (16) gives a system in debt and the long rate,

$$
\begin{aligned}
& \dot{D}=\left(\theta+p(p+\theta) \frac{D}{Y-G}\right) D+G-T(D, x), \\
& \frac{\dot{R}}{R}=\left(R-\theta-p(p+\theta) \frac{D}{Y-G}\right) .
\end{aligned}
$$

This system has a saddle point equilibrium. Its local dynamics around equilibrium are characterized in fig. 2. The stable arm $A A$ is upward sloping.

A decrease in $x$, i.e., a decrease in taxes at any level of debt, shifts the $\dot{D}=0$ locus to the right. The dynamics of adjustment to an unanticipated permanent decrease in $x$ are characterized in fig. 3. Starting from point $E, R$ jumps to point $C$, and $R$ and $D$ move over time along $C E^{\prime}$. The economic interpretation is straightforward: A decrease in $x$ decreases taxes, creating a deficit. This deficit increases debt over time and thus short-term rates. As debt increases, taxes increase reducing the size of the deficit. In the new steady state, debt and interest rates are higher. The initial deficits twist the term structure as short-term rates do not move but long rates move in anticipation of higher short rates later. The term structure flattens over time, until $R$ and $r$ are again equal in the new steady state.

The effects of anticipated deficits can also be characterized using fig. 3. A decrease in $x$, anticipated at $t$ to take place at time $t^{\prime}$ leads to a jump from $E$ to $B$ at $t$, a movement from $B$ to $C$ from $t$ to $t^{\prime}$ and a movement along $C E^{\prime}$ after $t^{\prime}$. Although the short-term rate does not move until $t^{\prime}$, the long rate

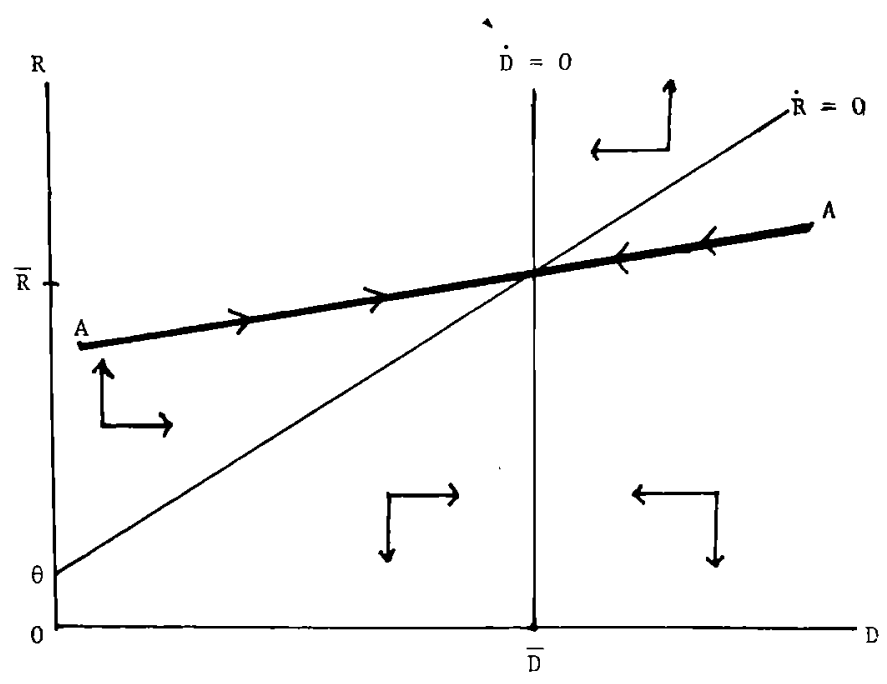

Fig. 2. Debt, deficits and interest rates in full employment. 


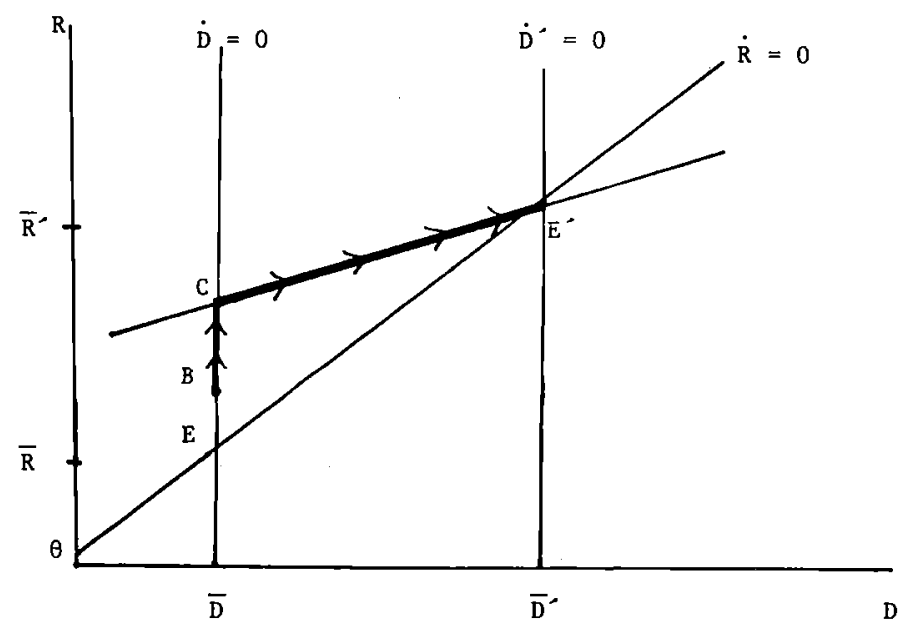

Fig. 3. Anticipated deficits, short and long rates.

increases at time $t$ to cancel the effects of anticipated lower taxes on human wealth.

To summarize, short rates depend in this full employment exchange economy on the current level of debt. Thus long rates depend on the sequence of anticipated debt, or equivalently, on the initial level of debt and the anticipated sequence of deficits. A sequence of higher deficits will initially increase long rates over short rates, leading over time to higher short and long rates. This analysis suggests that the current focus on deficits rather than on debt is possibly misdirected. It is true that the anticipated sequence of U.S. deficits is exceptional in peacetime and implies a large increase in the level of debt. The current level of debt as well as the anticipated levels of debt for the medium run are still much lower than at many times in the past.

\section{Deficits, interest rates, and output}

The focus is now on the potentially perverse effect of deficits on aggregate demand and on output. The strategy has been to remain close to the traditional Phillips curve augmented IS-LM, extending it only to introduce the distinction between short and long rates. ${ }^{14,15}$ The model is the following:

\footnotetext{
${ }^{14}$ An alternative strategy would have been to imbed the aggregate consumption function of the previous section in an otherwise Keynesian model. It would, however, be slightly more cumbersome analytically.

${ }^{15}$ This is a simplified and modified version of Blanchard (1981). It is very similar to a model developed by Cardoso (1983). It is related to a recent model by Turnovsky and Miller (1982) which treats the government budget constraint explicitly but maintains the fixed price assimulion.
} 
IS: $\quad Y=Y(R, g) . \quad Y_{R}<0, \quad Y_{g}>0$,

LM: $\quad i=L(Y, m / p), \quad L_{Y}>0, \quad L_{m / p}<0$,

$r^{*}=i-\dot{p}^{*} / p$

$$
\dot{R}^{*} / R=R-r^{*},
$$

PC: $\quad \dot{p}^{*} / p=\dot{p} / p=\theta(Y), \quad \theta_{Y}>0, \quad \bar{Y} \mid \theta(\bar{Y})=0$.

Aggregate demand is assumed to depend on the long term rate, current income, and an index of fiscal expansion $g$. Behind this specification is one important assumption and a technical short cut. The important assumption is that, although financial markets look forward, agents themselves do not; there is no direct effect of future income or future taxes on current aggregate demand (there will be an indirect effect through long real rates). We shall return to this assumption later. The short cut is that fiscal policy is summarized by a single index $g$. We know from the previous section that aggregate demand depends on each of the components of fiscal policy, taxes, spending, and debt. Thus a permanent increase in $g$ may correspond to a balanced budget increase in spending or, more interestingly, to initially higher deficits which resorb themselves as debt accumulates to reach a new higher steady state. ${ }^{16}$

The LM relation determines the short-term nominal rate as a function of income and real money balances $m / p$. The next two equations provide the links between this short-term nominal rate and the long real rate which appears in the IS. (19) defines the short real rate; asterisks denote expectations. (20), which was derived previously, relates short and long real rates. The last equation is a Phillips curve, relating inflation to the level of output.

The long-run equilibrium of this model is similar to that of the previous section:

${ }^{16}$ In the case where consumption is given by the consumption function derived in the previous section, and where consumers have static expectations, we can derive $g$ explicitly. In that case,

$$
\begin{aligned}
& C+G=(\theta+p)\left(D+\frac{Y-T}{r+p}\right)+G . \text { Thus, } \\
& g=(\theta+p)\left(D-\frac{T}{r+p}\right)+G .
\end{aligned}
$$

Rearranging and using the government budget constraint gives

$$
g=(\theta+p-r) D+\dot{D}+\frac{\theta-r}{r+p} T .
$$

If $r$ is close to $\theta$, this simplifies to

$$
g \doteqdot p D+\dot{D}
$$


If

$$
\begin{aligned}
& \dot{p}=\dot{p}^{*}=\dot{R}=0, \\
& \bar{Y}|\theta(\bar{Y})=0, \quad \bar{r}, \bar{R}| \bar{Y}=Y(\bar{R}, \bar{g}), \quad \bar{r}=\bar{R} \\
& \bar{p} \mid \bar{r}=L(\bar{Y}, m / \bar{p})
\end{aligned}
$$

Fiscal expansion has no long-run effect on output but increases the steady state rate of interest. Prices adjust so that real money balances are consistent with the new rate of interest.

To characterize the dynamics of output and interest rates to a fiscal stimulus, we can reduce the system to a system in $R$ and $p$. Replacing the IS, the LM and the Phillips curve in the interest rate equations (19) and (20),

$$
\dot{R} * / R=(R-r),
$$

where $r$ is given by

$$
r=L(Y(R, g), m / p)-\theta(Y(R, g)) .
$$

The effect of output on the short-term rate is a priori ambiguous: an increase in output increases both the short term nominal rate and expected inflation. We shall assume that the nominal rate effect dominates, i.e., that $L_{Y}-\theta_{Y}>0$, so that an increase in output increases the short real rate. ${ }^{17}$ In this case, fiscal expansion increases short real rates; an increase in the long real rate decreases output and decreases short real rates. Finally, an increase in prices decreases real money balances, increasing the short real rate.

The other relation follows from the IS and the Phillips curve,

$$
\dot{p} / p=\theta(Y(R, g))
$$

Fiscal expansion increases output and inflation, while an increase in long real rates decreases output and inflation.

The analysis can again be carried out most easily with a phase diagram. The system has a saddle point equilibrium so that given $p$, there is a unique value of $R$ consistent with convergence to steady state. The local dynamics around equilibrium are characterized in fig. 4. The stable arm $A A$ is upward sloping.

The dynamic effects of a fiscal expansion, that is, of an increase in $g$, are characterized in fig. 5. We first characterize the dynamics technically: The system jumps from $E$ to $C$ and converges to $E^{\prime}$ over time. From the Phillips curve, as $\dot{p}$ is positive, output initially increases. From the IS, as $R$ increases along $C E^{\prime}$, output decreases along $C E^{\prime}$. Finally, from the arbitrage equation, as $\dot{R}$ is positive, $R$ is larger than $r$ along $C E^{\prime}$. Thus a fiscal expansion leads

\footnotetext{
${ }^{17}$ (Saddle point) stability of the system does not depend on this assumption.
} 


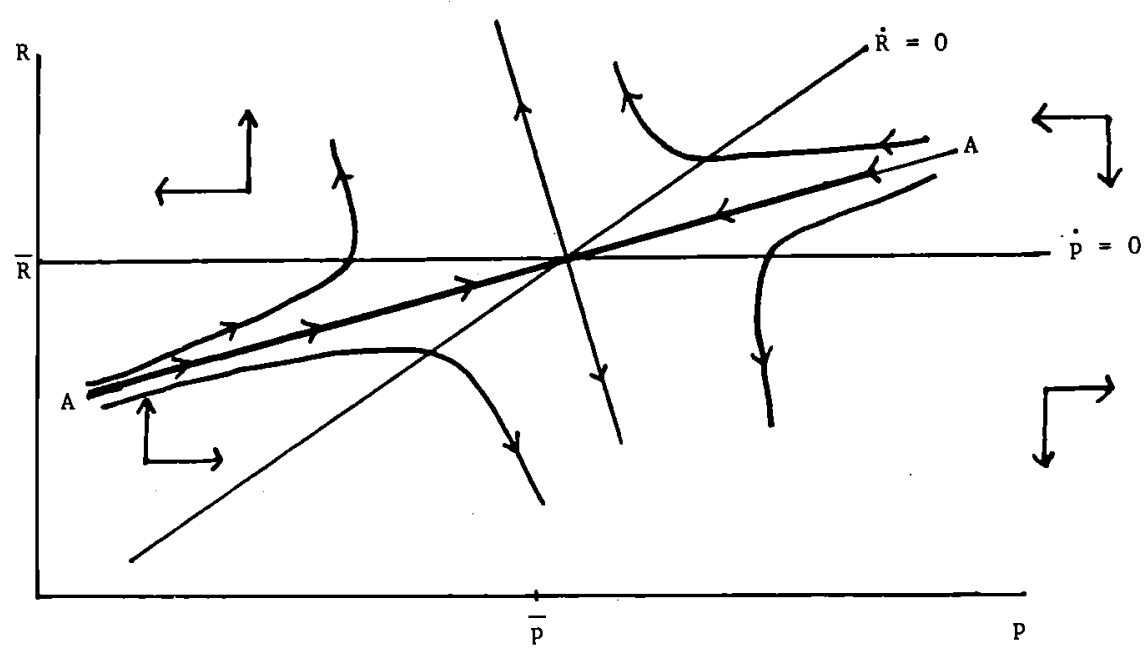

Fig. 4. Dynamics of interest rates and prices.

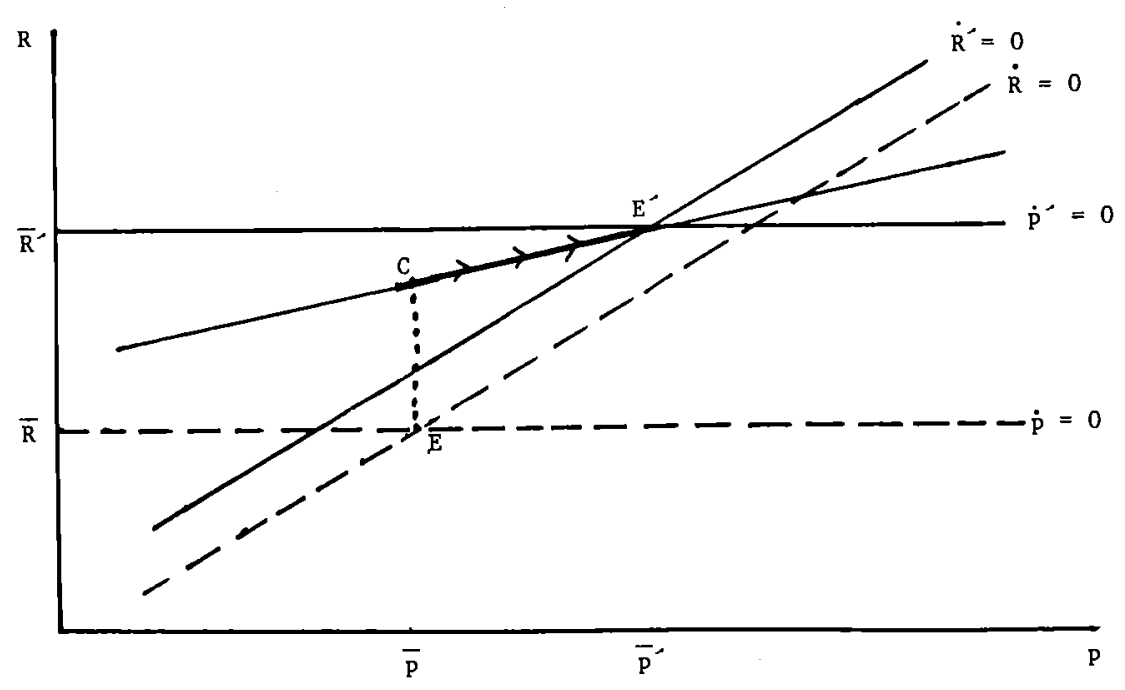

Fig. 5. Effects of a fiscal expansion.

initially to an increase in short real rates and output; over time, output goes back to normal and short real rates increase further. It is this increasing sequence of short rates which explains the initial jump in long rates. Fiscal expansion, therefore, twists the term structure, increasing long rates over short rates. This leads to more crowding out than would be predicted by models which do not distinguish between short and long rates. It does not, however, lead to perverse effects of a fiscal expansion on output. 
Consider however a more realistic experiment, in which deficits instead of being suddenly larger, increase slowly through time. Instead of a jump of $g$ from $\bar{g}$ to $\bar{g}^{\prime}$ as before, consider instead the following fiscal expansion: until time $t, g$ is equal to, and expected to remain equal to $\bar{g}$. At $t$, anticipations change and the new actual and anticipated path of $g$ is

$$
\dot{g}=\Psi\left(\bar{g}^{\prime}-g\right), \quad \Psi^{\prime}>0 .
$$

Such a path for $g$ corresponds, for example, to deficits which initially grow over time before resorbing themselves as debt accumulates to a new, higher, steady state level. The path of adjustment is characterized in fig. $6 . R$ jumps from $E$ to $C ; R$ and $p$ then adjust along $C D E^{\prime}$ over time. The behavior of $R$, $r$, and $Y$ is given below the phase diagram; whether $r$ further decreases after its initial decrease is ambiguous. ${ }^{18}$

Thus this type of fiscal expansion has temporarily perverse effects on output. The reason is simple. The initial current fiscal stimulus is small. It is, however, anticipated to be large and thus to lead to high short real rates later. As a result, long real rates increase, leading to a decrease in aggregate demand which more than offsets the fiscal expansion, at least initially. Thus, the model tells us, the U.S. fiscal program and its growing projected deficits could well be initially contractionary. The model also suggests a way in which fiscal policy could be improved. As current deficits are expansionary and anticipated deficits contractionary, shifting of government spending towards the present would, by increasing current deficits and decreasing future deficits, increase aggregate demand and help the recovery.

It is, however time to return to the specification of aggregate demand. What if agents are forward looking and take into account the anticipated sequence of taxes and income, as in the previous section? First, if they take into account the anticipated sequence of taxes, a slow increase in deficits is not equivalent to a slow effect of fiscal expansion on aggregate demand, to a slow increase in $g$ : agents will realize that the present value of their tax burden has decreased and this will increase aggregate demand even if current deficits are still small. Second, if they take into account future income, the anticipation of temporarily higher output and income may also increase aggregate demand initially. ${ }^{19}$ This effect will be stronger, the smaller the effect of liquidity constraints, the larger the effect of fiscal expansion on output - if, for example, the economy is expected to have substantial unemployed resources for many years to come. Whether these effects more than offset the interest rate effects is theoretically ambiguous. If these income effects dominate, the large U.S. anticipated deficits are expansionary in spite of their effect on current long-term real rates.

\footnotetext{
${ }^{18}$ The algebraic derivation of these paths is straightforward but extremely tedious. The method is identical to that used in appendix B in Blanchard (1981).

${ }^{19}$ This possibility is partially explored in Blanchard (1981) by the introduction of a stock market which affects aggregate demand.
} 

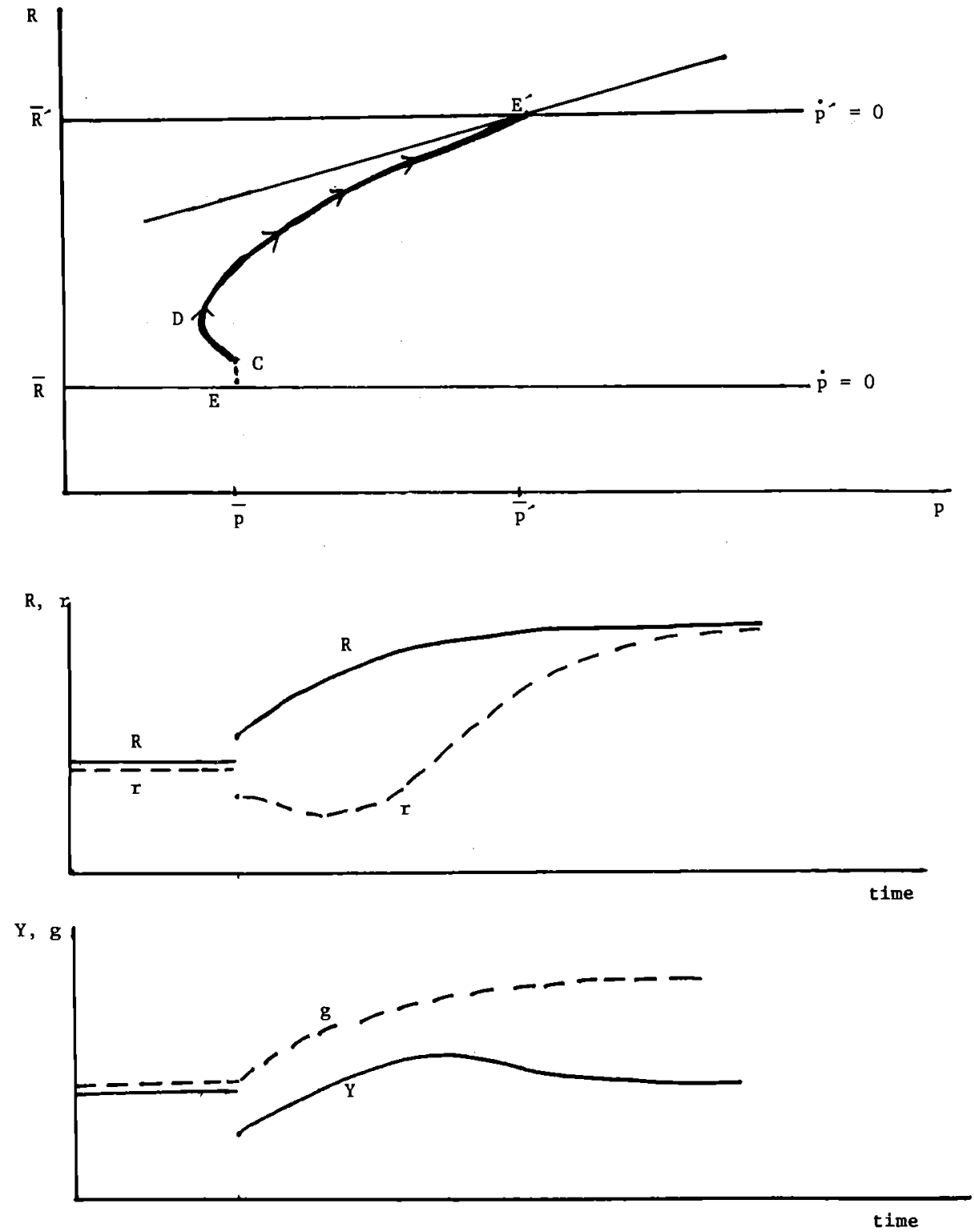

Fig. 6. Effects of an anticipated fiscal expansion. 


\section{Conclusion}

What do we make then of the new view that fiscal deficits hurt rather than help the recovery? We have found that the issue of sustainability has indeed, because of the increase in real rates, become a relevant issue although probably not yet a pressing one. We have found that in turn, at full employment, short real rates increase with the level of debt; as a result, prolonged deficits lead to increasing real rates, thus to long rates being higher than short rates. We have finally found that, if output responds to aggregate demand, anticipations of growing deficits may be initially contractionary.

The three models presented in this paper are simple enough that they can withstand added complexity and realism without loosing analytical tractability. In particular integrating the first and the second, and the second and third, would probably be quite useful.

Finally, this paper has focused on the effects of deficits in closed economies. One major issue is, however, that deficits are anticipated to be much larger in the U.S. than in the other countries. This would lead in closed economies to large differences in real rates. It is likely to lead, in open economies with capital mobility, to large movements in exchange rates. I believe that a two-country extension of the second model will prove useful to analyze this issue.

\section{Appendix: Derivation of the aggregate consumption function}

Individual consumption. Denote by $c(t, s), y(t, s), w(t, s), h(t, s)$ consumption, non-interest income, non-human wealth, and human wealth of an agent born at time $t$, as of time $s$.

At time $s$, the agent maximizes

$$
\mathrm{E}_{s} \int_{s}^{\infty} \log c(t, v) \mathrm{e}^{(s-v) \theta} \mathrm{d} v
$$

Under the assumption of a constant instantaneous probability of death $p$, and of subjective certainty about $c(t, v), v \geq t$, this is equivalent to

$$
\max \int_{s}^{\infty} \log c(t, v) \mathrm{e}^{(s-v)(\theta+p)} \mathrm{d} v
$$

The 'budget constraint' faced by the agent at time $s$ is, if the rate on actuarial notes is $r(\mu)+p$ at time $\mu$ [the discussion and justification of the implicit 
transversality condition is given in Yaari $(1965$, p. 146)],

$$
\begin{aligned}
& \int_{s}^{\infty} c(t, v) \exp \left\{-\int_{s}^{v}(r(\mu)+p) \mathrm{d} \mu\right\} \mathrm{d} v \\
& =w(t, s)+\int_{s}^{\infty} y(t, v) \exp \left\{-\int_{s}^{v}(r(\mu)+p) \mathrm{d} \mu\right\} \mathrm{d} v .
\end{aligned}
$$

The solution to this maximization problem is

$$
\begin{aligned}
& c(t, s)=(p+\theta)\left(w(t, s)+\int_{s}^{\infty} y(t, v) \exp \left\{-\int_{s}^{v}(r(\mu)+p) \mathrm{d} \mu\right\} \mathrm{d} v\right), \\
& \mathrm{d} w(t, s) / \mathrm{d} s=(r(s)+p) w(t, s)+y(t, s)-c(t, s) .
\end{aligned}
$$

Aggregate consumption. Denote aggregate consumption, aggregate noninterest income, aggregate non-human wealth and aggregate human wealth at time $s$ by $C(s), Y(s), W(s)$ and $H(s)$. Then,

$$
\begin{aligned}
& C(s)=\int_{-\infty}^{s} c(t, s) \mathrm{e}^{(t-s) p} \mathrm{~d} t \Rightarrow \\
& C(s)=(\theta+p)\left[W(s)+\int_{-\infty}^{s} \mathrm{e}^{(t-s) p}\left(\int_{s}^{\infty} y(t, v) \exp \left\{-\int_{s}^{v}(r(\mu)+p) \mathrm{d} \mu\right\} \mathrm{d} v\right) \mathrm{d} t\right],
\end{aligned}
$$

where

$$
W(s)=\int_{-\infty}^{s} w(t, s) \mathrm{e}^{(t-s) p} \mathrm{~d} t .
$$

Under the assumption that non-interest income is the same for all agents alive, $y(t, v)=p Y(v) \forall t$ and all agents alive have the same human wealth. Thus (A.5) can be rewritten as

$$
\begin{aligned}
& C(s)=(\theta+p)[W(s)+H(s)], \\
& H(s)=\int_{s}^{\infty} Y(v) \exp \left\{-\int_{s}^{v}(r(\mu)+p) \mathrm{d} \mu\right\} \mathrm{d} v,
\end{aligned}
$$

Differentiating $W(s)$ with respect to time gives

$$
\mathrm{d} W(s) / \mathrm{d} s=w(s, s)-p W(s)+\int_{-\infty}^{s} \frac{\mathrm{d} w(t, s)}{\mathrm{d} s} \mathrm{e}^{(t-s) p} \mathrm{~d} t .
$$


Using (A.4) and $w(s, s)=0$ gives

$$
\mathrm{d} W(s) / \mathrm{d} s=r(s) W(s)+Y(s)-C(s) .
$$

Eqs. (A.3) and (A.4) are eqs. (4) and (5) in the text, eqs. (A.6) and (A.7) are eqs. (6) and (7) in the text.

\section{References}

Barro, Robert J., 1974, Are government bonds net wealth?, Journal of Political Economy 82, no. $6,1095-1117$.

Blanchard, Olivier J., 1981, Output, the stock market and interest rates American Economic Review 71, no. 1, 132-143.

Cardoso, Eliana, 1983, Fiscal policy and asset prices, Mimeo.

Hubbard, G., 1983, 'Structural' government budget deficits: Reappraisal and implications, Mimeo.

Tobin, James, 1967, Life cycle saving and balanced growth, in: Ten studies in the tradition of Irving Fisher (Wiley, New York).

Turnovsky, Steven and M. Miller, 1982, Bond market efficiency and macroeconomic policy in a simple dynamic model, Mimeo.

Yaari, Menahem E., 1965, Uncertain lifetime, life insurance and the theory of the consumer, Review of Economic Studies 32, 137-150. 


\title{
COMMENTS
}

\author{
'Current and Anticipated Deficits, Interest Rates and Economic Activity' \\ by Olivier Blanchard \\ E. MALINVAUD \\ INSEE, 75675 Paris, France
}

To which extent should we revise our ideas on the impact of fiscal policy when its anticipated consequences are taken into account by the markets? This is indeed a quite important question for the progress of our macroeconomic theory. Before anything else, we must thank Olivier Blanchard for giving us an opportunity of discussing this important issue.

We know that the question was raised about ten years ago, as part of the critiques that attacked previous conceptions on the efficiency of Keynesian policies. We also know the answer given by Robert Barro in his famous article entitled 'Are government bonds net wealth?', claiming that there is no persuasive case for treating government debt as increasing perceived household wealth. This conclusion was said to imply the inefficiency of an expansionary fiscal policy financed by the issue of such bonds.

One should never have drawn this conclusion from Barro's model since it assumed full employment whereas the problem is precisely to know whether fiscal policy can reduce disequilibrium on the labor market. But on the one hand the question was worth raising, on the other hand Barro's model is stimulating for thinking about some aspects of the relationship between government debt and private saving.

A fully convincing theory of the impact of fiscal policy under perfect foresight is clearly quite difficult to build. It should indeed combine three features, each one of them taken alone already making modelling delicate: a proper representation of rational behavior by agents, an adequate formalization of market disequilibria, a long term perspective with in particular a correct treatment of stock-flow relationships. It is, therefore, not surprising that such a theory does not yet exist.

In order to make progress toward it, a good strategy consists in dealing at this stage with models that still neglect some important complications, but also in trying such a variety of models that we may hope to grasp all relevant aspects of the subject, although not yet within an integrated framework. This is precisely the strategy adopted by Blanchard since the 
three theoretical sections of his paper adopt three different approaches. He explicitly recognizes that these three sections are not integrated with one another. He tells us in his conclusion that integrating the first and the second (models), and the second and third, would probably be quite useful', but he does not dwell on this somewhat puzzling and not committing statement (would not integrating the first and third models be useful?).

The third model is the most interesting one for answering my main queries. But before considering it, I must say a few words about the second one.

Section 4, presenting this second model, is a quite neat and interesting piece of theoretical work. Adopting admittedly heroic simplifications proposed by $M$. Yaari, it succeeds in dealing with a dynamic equilibrium under rational expectations, while starting from individual life cycle behavior of consumers. It shows that, when consumers have a non-zero probability of dying, Barro's equivalence does not hold and an increase of government debt leads to an increase of long term interest rates, which changes the resulting equilibrium.

I am not surprised by the result, which fits well within the many cases that were considered by Barro in his article, not all of which implying neutrality of government debt. I even wonder whether one should not try to change the assumptions of the present model in one respect, so as to make them more realistic while keeping most of its simplicity. If consumers were subject to two risks instead of one, that of becoming inactive and not only that of dying, an important inducement for saving would be recognized in the model whereas it does not appear in the present form.

But the model of this section 4 assumes market clearing, aggregate demand exactly exhausting at any time the exogenously given supply. As I said at the beginning, this cannot be the proper framework for dealing with the impact of fiscal policy on output and unemployment.

I am, therefore, turning to section 5 which considers fiscal policy within an almost traditional IS-LM model augmented with a Phillips curve. The novelty of the model is the distinction between the long term real interest rate occuring in the IS equation and the short-term nominal interest rate of the LM equation; the relationship between the two is ruled by perfect foresight market equilibrium equations given by (19) and (20) on page 20 . In the same way as in the models used in the early sixties, the long-term equilibrium output is given by the Phillips curve; namely, it is this output level that is consistent with a constant price level.

The conclusion drawn from the model is that current government deficits are expansionary but growing deficits are initially contractionary. More precisely:

- A sudden unanticipated increase of government spending $g$ to a higher permanent level leads to a jump of long term interest rate and to a 
progressive increase of the price level up to a new equilibrium, while there is a temporary expansion of output; there will be more crowding out than would be predicted by models which do not distinguish between short and long interest rates, but no perverse effect of a fiscal expansion on output.

- On the other hand, if the decision is suddenly taken that government spending will from now on progressively grow to a higher level according to the equation of page 23, then the long term interest rate will immediately jump to a higher level on the way to its new equilibrium level; this will have a depressing effect on demand and will initially dominate the stimulating impact of increasing government spending.

Discussing this section, I must first stress the great pedagogical value of the model. It is excellent for exhibiting in a simple way one aspect of the role of anticipations on the short term equilibrium. In this respect, I find it more convenient than the model presented by Blanchard in his 1981 American Economic Review paper, in which stock prices were added to interest rates as market variables. The extra complication that this implied does not seem to me to be worth it.

With respect to the object of the paper the model is, however, subject to two limitations that should be noted. In the first place, its Phillips curve and the implied determination of equilibrium output are subject to criticism. I do not need to remind you of all the arguments showing why the Phillips curve may shift when anticipations are revised. I do not consider this comment as being devastating, since $I$ know that, at the present time and for decades to come, macroeconomic theory has to be eclectic. But the limitation should be kept in mind; it means that the conclusions are well founded only when expectations about the long-term trend of inflation are insensitive to short term fluctuations of prices, as long as expectations on the money supply do not change (strictly speaking the paper assumes that long term expectations imply no inflation and a constant money supply).

The second limitation is made explicit on page 18: although financial markets look forward, agents themselves do not, in the sense that aggregate private demand does not directly react to future income and future taxes, but only to future prices and interest rates. The result would have been different if the framework of section 4 had been applied to the determination of aggregate demand and this is precisely why integration of sections 4 and 5 would be illuminating.

Blanchard speculates in section 5 about what changes would then be brought to his results. He convincingly argues that expectation of higher output and incomes will raise aggregate demand initially and that this income effect may dominate the interest effect, which was shown to be initially perverse in the case of a progressively increasing government deficit.

From this interesting section $5 \mathrm{I}$ draw the conclusion that the approach of the paper is quite appropriate for dealing with the important issue of 
knowing how anticipations react on policy changes and how this reaction affects the impact of such changes. But there is still a good deal of work to be done, in order to apply the approach to various models exhibiting other relevant aspects of macroeconomic realities.

I shall be very brief in my comments on section 3 that considers the question of knowing how a present government deficit will be sustainable in the long run. Sustainability fails if future payments of interest on government debt will have to grow indefinitely as a result of present deficit. This notion of a possible lack of sustainability relates to another one, namely that taxes cannot be too high and government spending too low. The paper formalizes the idea in two simple alternative ways, taking as given, and constant through time, the maximum aggregate value of taxes that can be collected and the minimum value of non-interest government spending that has to be made.

It should be clear that other formalizations of the issue could be explored, concerning, for instance, the case of a growing economy, or the case in which the maximum concerns not the value of the flow of taxes but the rate of taxation, which would make a difference if the long-run value of output depends on present deficit.

How persuasive are such theoretical models for changing the views of people concerned with the present increase of interest charges in government budgets? I do not know. But the models are worthy of discussions in much larger circles than the present one. 


\title{
COMMENTS
}

\section{'Current and Anticipated Deficits, Interest Rates and Economic Activity' by Olivier Blanchard}

\author{
Stephen MARRIS \\ Washington, DC 20036, USA
}

It is obviously no accident that this paper addresses some issues at the heart of recent policy debate. All the discussions on macroeconomic policy in the OECD over the past two years have been bedevilled by the fact that about half of the people have been arguing that the best way to get out of a recession is to increase budget deficits, while the other half has been arguing that the best way is to reduce them. Actually, half of them have also been arguing that the best way to get out of a recession is to speed up the growth of the money supply, while the other half wants to slow it down - but this is a different story to which I will return only briefly.

As the author himself points out, the analysis of the sustainability of deficits in section 3 is rather static and oversimplified. On the one hand, allowing for positive GNP growth would provide most countries with significantly more room than suggested by eq. (3) before they found themselves caught in a Ponzi game. On the other hand, many countries could already be in a position where it might not be politically feasible to cut back deficits fast enough to match the cyclical reduction in the excess of savings in the private sector as we move into a recovery phase. If so, these deficits are not 'sustainable' in the sense that they will inevitably lead, either to crowding out with inadequate investment, or to monetisation with accelerating inflation.

This is where Blanchard's $\alpha$ term comes in - the maximum politically feasible rate at which today's deficit can be reduced. This is a very useful construct which deserves further thought and elaboration by both economists and political scientists.

A first suggestion would be to divide $\alpha$ into $\alpha G$ and $\alpha T$, the maximum politically feasible rates of reducing public expenditure or increasing taxes. In most countries $\alpha G$ is probably more severely constrained than $\alpha T$. Increases in expenditure are often deeply embedded in the legislation and administration of social programmes; and indexation and demography add 
to the momentum. It is generally politically easier, at least in the short term, to reduce deficits by raising taxation, partly because the pain is spread out more thinly through the electorate. There are, of course, economic constraints on the tax side, e.g., if higher taxes generate 'tax push' inflation or squeeze profits and depress investment, but these take some time to make themselves felt.

A second thought is that $\alpha$ no doubt varies quite a lot between countries. In parliamentary democracies with a clear majority the government can increase taxes almost at will. Indeed in a centralised country like France the authorities have a remarkably strong grip on both revenues and expenditure. In the United States, however, recent events have vividly illustrated the old adage that 'the Administration proposes, but Congress disposes'.

A third comment is that $\alpha$ should be engraved on the gravestone of Reagonomics. The basic idea was that the only way to reduce public expenditure is to reduce taxes. In certain circumstances this may be correct in terms of political realities. But anyone trying this experiment should be sure to get their sums right. If you knock $\$ 70$ billion off your tax revenues, you may well be able to use the threat of large deficits to push through some cuts in expenditure. But if you are overambitious you will run head on into $\alpha G$. If so, you will not be able to convince the financial markets that there is any politically feasible way of bringing the large budget deficit under control - and this, of course, is what has happened.

Blanchard tries to model the consequences of this for interest rates and economic activity in sections 4 and 5. Put very simply, eqs. (21) and (22) yield a world in which if action is taken which will lead to large deficits in the future, this creates the expectation of a future rise in short-term real interest rates which pushes up the long-term real rate now. If, in addition, the initial fiscal stimulus is small, its positive effects on activity could be more than swamped by the negative effect of these higher long-term rates. This model is not only elegant, it fits suspiciously well with what many commentators felt was happening to the United States economy at the time Blanchard was writing his paper.

One attractive feature of this model is that it calmly assumes that: 'although financial markets look forward, agents do not'. This seems to me to be a very sensible way to put some realism back into the wreckage created in the world of theoretical economics by the rational expectations school. It should be obvious that the man in the street does not spend all his time trying to work out with great ingenuity the ultimate consequences of every government action; but financial markets (and exchange markets) do. ${ }^{1}$

It is important to note that Blanchard's model does not seem to be able to explain why real short-term rates have remained so high during this

\footnotetext{
${ }^{1}$ For a similar approach to current macro-economic problems, see Andrea Boltho, 'Is Europe Caught in an Expectations Trap?', Lloyds Bank Review, April 1983.
} 
recession. In other words, it leaves open the other half of the macro-policy debate: was US monetary policy unduly tight because of a failure to anticipate the magnitude of the recession-induced drop in velocity? What is interesting, however, is that it tackles directly the other much disputed question of why nominal long-term rates have not fallen more given the sharp drop in inflation. The answer suggested is that it is not (only) because of the downward stickiness of inflationary expectations, but also because of the emergence of high interest rate expectations related to the prospect of large and growing structural budget deficits. ${ }^{2}$

If this model is correct, what are the policy implications? In terms of economics it is simple: what is needed is action now to reduce budget deficits later. Various ideas have been put forward along these lines. The Institute for International Economics ' 26 economists' suggested 'front-loading' inevitable expenditure increases, while 'back-loading' the corresponding tax increases. ${ }^{3}$ The Chairman of the Council of Economic Advisors has proposed a contingency plan to trigger the necessary tax increases if, as he assumes, the deficit problem does not solve itself as the supply-siders would like to believe.

But this is where we run into the politics of the $\alpha$-factor with a vengeance. Nobody really believes that the US Congress is prepared to commit itself firmly to doing something nasty to its electors at some point in what is, in political terms, the dim and distant future. Indeed, more fundamentally, political realists are inclined to dismiss such ideas as pie in the sky on the grounds that if we cannot summon the political will to get public expenditure under control now, when deep recession and massive deficits create a strong sense of crisis, then we never will. 'Father, please let me stop sinning, but not just yet' may be good economics, but it is lousy politics. This is a real dilemma, and both sides clearly have a good case. ${ }^{4}$

A final comment: could these models explain why other countries have had abnormally high interest rates? Apparently not, because as Blanchard points out in section 2, when adjusted for inflation and low levels of activity, the structural budget position of most of the other major countries looks much better than that of the United States, and the prospects are that it will improve rather than deteriorate over the recovery period.

But an alternative 'closed economy' explanation is often given for a postulated negative effect of large deficits on interest rates, namely the consequences of the rapid accumulation of debt from past deficits. The

\footnotetext{
${ }^{2}$ The opening of financial future markets provides some indication of what has been happening to expected future rates of interest. It would be interesting to compare this with, e.g., Michigan survey data on what has been happening to inflationary expectations, to see whether this provides any empirical confirmation for this thesis.

${ }^{3}$ Promoting World Recovery. A statement on global economic strategy by 26 economists from 14 countries, Institute for International Economics, Washington, DC, December 1982.

${ }^{4}$ The 1983 Canadian budget, which combined a short-term stimulus with quite strong action to reduce expenditure and raise revenue two and three years out, was an interesting attempt to resolve this dilemma. Although it got quite a good reception, it may well not get a fair trial because of events in the United States.
} 
argument is essentially that the higher the ratio of public debt to GNP, the higher the interest rate needed to finance a given budget deficit.

It is true that the ratio of government debt to GNP has increased strongly in some countries since the first oil crisis. Taking figures from a recent article by Robert Price and Jean-Claude Chouraqui, ${ }^{5}$ which sets out a fascinating cross-country quantitative analysis of several of the issues dealt with in the Blanchard paper, we get:

\begin{tabular}{lrrr}
\hline & Japan & Germany & UK \\
\hline Ratio of central government debt to GNP (percent): & & & \\
1973 & 11 & 7 & 44 \\
1982 & 43 & 19 & 42 \\
Change in percentage points & +32 & +12 & -2 \\
Of which due to: & +37 & +12 & +28 \\
Net new borrowing excluding interest payments & -1 & +2 & -23 \\
'Inflation tax' & -4 & -2 & -7 \\
Other $^{7}$ & & \\
\hline
\end{tabular}

It is interesting to note that the size of current budget deficits was not the only important factor. The debt ratio fell in the United Kingdom even though it was running deficits much larger than in Germany and threequarters as large as in Japan over this period, the main factor being the heavy 'inflation tax' on holders of government debt.

Whatever the reasons, does the sharp rise in the ratio of government debt to GNP in Japan and Germany over this period help to explain the abnormally high levels of interest rates during the 1981-82 recession? Basically I am skeptical. In part this is because the historical record shows that different countries - and the same countries at different times - have been able to live with remarkably different ratios of debt to GNP. It is also because an alternative explanation lies readily to hand. The high level of interest rates outside the United States can be explained, not in terms of the size of budget deficits outside the United States, but rather in terms of the size of the actual and potential budget deficit in the United States, working its way out via a non-accommodating monetary policy to high interest rates, a strong dollar, and very large potential capital inflows.

Indeed, the question of how excesses or deficiencies in the balance of $e x$ ante private savings versus public dissaving get transmitted from country to country has become central to international economic policy making. As Blanchard suggests at the end of his paper, it would be interesting to try to model it. But given the key role that exchange rates and exchange-rate expectations play in this process, and the weakness of virtually all attempts to model exchange-rate behaviour, this is likely to be a difficult task.

\footnotetext{
${ }^{5}$ Robert Price and Jean-Claude Chouraqui, 'Public Sector Deficits: Problems and Policy Implications', OECD Economic Outlook, Occasional Studies, Paris, June 1983.

${ }^{6}$ Interest payments less the reduction in the real value of government debt due to inflation.

${ }^{7}$ Effect of real GNP growth and relative price changes.
} 
